УДК 340.113 .2

О.А. Пестова
адъюнкт
Уральский юридическй институт Мвд России
Российскя Федерация, 620017, г. Екатеринбург, ул. Корепина, 66
ОяСІD: 0000-0002-0164-7696. E-mail: lelia_77777@mail.ru
Особенности отдельных типов
распорядительных делопроизводственных
документов органов внутренних дел
(историко-правовой аспект)

Аннотация: Статья посвящена анализу отдельных типов распорядительных делопроизводственных документов органов внутренних дел в советский период. Автор статьи указывает, что распорядительные делопроизводственные документы, содержащие нормы права, но не являющиеся нормативными, являются также и правовыми актами управления. Именно последние становятся предметом исследования учёных в области административного права, их научные положения необходимы для уяснения существа ведомственного нормотворчества. Поэтому делопроизводственные документы данного рода следует анализировать, используя междисциплинарный подход. Автор, рассматривая отдельные типы названных документов: указаний, циркуляров, директив и правовых предписаний, обращает внимание на период применения указанных документов в практике работы органов, особенности их содержания и оформления. Представленный историко-правовой анализ позволяет сохранять преемственность при осуществлении правового регулирования в органах внутренних дел, единообразное осуществление ведомственного нормотворчества.

Ключевые слова: делопроизводство, распорядительные документы, история советской милиции, органы внутренних дел, типы документов.

Для цитирования: Пестова О.А. Особенности отдельных типов распорядительных делопроизводственных документов органов внутренних дел (историко-правовой аспект) // Вестник Санкт-Петербургского университета МВД России. - 2019. - № 2 (82). - С. 79-85. DOI: 10.35750/2071-8284-2019-2-79-85.

Olga A. Pestova

Graduate

Ural Law Institute of the MIA of Russia

66, Korepina str., Ekaterinburg, 620057 Russian Federation.

ORCID:0000-0002-0164-7696.E-mail: lelia_77777@mail.ru

\title{
Features of certain types of administrative records of internal Affairs bodies (historical and legal aspects)
}

Annotation: The article is devoted to the analysis of certain types of administrative documents of the internal Affairs bodies in the soviet period. The author of the article points out that administrative documents containing the rules of law, but not being normative are also legal acts of management. These acts are the subject of research of scientists in the field of administrative law, their scientific 
provisions are necessary to understand the essence of departmental rulemaking. That is why the consideration of documents of this kind should be considered using an interdisciplinary approach. The author, considering separate types of the called documents: instructions, circulars, directives and legal instructions, pays attention to the period of application of the specified documents in practice of work of bodies, features of their contents and registration. The presented historical and legal analysis allows to maintain continuity in the implementation of legal regulation in the bodies of internal Affairs, the uniform implementation of departmental rulemaking.

Keywords: office work, administrative documents, the history of the soviet police, the internal Affairs bodies, types of document.

For citation: Pestova O.A. Features of certain types of administrative records of internal Affairs bodies (historical and legal aspects) // Vestnik of St. Petersburg University of the Ministry of internal Affairs of Russia. - 2019. - № 2 (82). - P. 79-85. DOI: 10.35750/2071-8284-2019-2-79-85.

Распорядительные делопроизводственные документы в органах внутренних дел обладают определённой спецификой с точки зрения их нормативности. Более того, распорядительные документы являются предметом исследования не только учёных, специализирующихся на общей теории права, но административистов, однако данная группа документов в административном праве именуется правовыми актами управления.

Так, специалистами в области административного права правовой акт управления рассматривается как юридически властное волеизъявление субъекта управления, который всегда влечёт юридические последствия $[8$, c. 8$]$.

В данной статье рассматривается группа распорядительных делопроизводственных документов, которые содержат нормы права, но не являются по форме и порядку принятия нормативными, поскольку возможность их издания в определённый исторический период не была предусмотрена в законодательстве. Названные виды актов могли содержать правовые предписания наряду и с общеруководящими установками, и с волеизъявлениями о необходимости принятия решения в рамках одного вопроса нормами индивидуального характера.

Таким образом, общей гранью при исследовании делопроизводственных документов как правовых актов управления является их дифференциация в зависимости от их юридических свойств. Однако в пред- мет исследования специалистов в области административного права не входит изучение истории формирования отдельных типов делопроизводственных документов, а также предметный анализ их содержания, что для общей теории права является первостепенной задачей, поскольку необходимо вырабатывать четкий понятийный аппарат для единообразного правового регулирования. При этом стоит заметить, что провести различия между актами, содержащими нормы права, но не являющимися по форме и порядку принятия нормативными, и актами ненормативными в историческом контексте на примере системы органов внутренних дел довольно сложно, что обусловлено изменением подходов к предмету и порядку урегулирования вопросов ведомственного характера в советский период.

Распорядительные документы, содержащие нормативные предписания, являясь в то же время и нормами административного права, которые относятся к актам, принимаемым органами исполнительной власти, не включая акты, принимаемые иными государственными органами [1, с. 53].

При этом нормы этого вида подразделяются на нормы, регулирующие вид деятельности, и нормы управления соответствующей деятельностью, которые заключаются в соответствующие типы делопроизводственных документов. Одни регулируют деятельность (поскольку орган, издающий данный документ, обладает компетенцией на данное регулирование, соответственно, придает 
нормативность норме управления), вторые обеспечивают управление деятельностью, отражая в своем типе специфику данного управления. Делопроизводственные документы в данном случае представлены как «средства юридического воздействия со стороны органов исполнительной власти, которые получают выражение в административных актах» $[5$, с. 135].

Эффективность воздействия права на управление органов внутренних дел во многом зависит от того, насколько систематично изучается учёными-правоведами и сотрудниками государственного аппарата действенность конкретных правовых актов и содержащихся в них норм [2, с. 30].

Для подтверждения указанных положений целесообразно рассмотрение исторического развития отдельных типов распорядительных делопроизводственных документов, нормативная и правовая составляющая которых представляется наиболее спорной.

Правовая природа указаний на разных этапах развития органов внутренних дел была различна. С одной стороны, ряд документов данного типа можно отнести к подзаконным нормативно-правовым актам, с другой - к актам, содержащим правила поведения, обязательные только для отдельных субъектов - должностных лиц - сотрудников соответствующих подразделений органов внутренних дел.

Круг вопросов, разрешаемых указаниями, чрезвычайно широк. Именно поэтому данный тип актов можно отнести к типу распорядительных документов делопроизводства, регламентирующих вопросы различных предметных полномочий органа внутренних дел.

Указания в системе органов внутренних дел применялись как форма акта с начала 1940-х годов. При этом наблюдалось применение смешанных типов актов, например, инструктивных указаний ${ }^{1}$, в рам-

\footnotetext{
${ }^{1}$ Инструктивные указания по сбору, обработке и использованию в пищу съедобной дикорастущей и огородной зелени (утв. НКВД СССР 1 июня 1943 г.) [Электронный документ] // СПС «Консультант Плюс».
}

ках которых предлагались рекомендации по осуществлению определённых действий: «Рекомендуется, по возможности, сменять один сорт потребляемой зелени и овощей другим». Инструктивный характер акта был обусловлен описанием свойств растений, содержанием в них полезных для человека элементов и описанием признаков растений: по цвету, вкусу, запаху и т.п. Позднее были разработаны даже инструктивно-методические указания ${ }^{2}$ в которых был описан и способ осуществления отдельных функций органа государственной власти. Применялись и директивные указания, например, по организации военнопленных в лагеря ${ }^{3}$.

Особенностью директивных указаний является их непосредственное (прямое) разрешение вопросов. Функция прямого (директивного) регулирования обеспечивает режим централизованного административного управления [9, с. 14], однако в литературе нет единого определения данного понятия.

Традиционно в указаниях использовалась такая структура акта, при которой давалось описание ситуации, складывающейся в органах внутренних дел, например, политико-моральное состояние, отмечались достоинства и недостатки, давались рекомендации по улучшению работы ${ }^{4}$.

В 1970-е годы в системе общего делопроизводства было определено, что указание должно содержать нормы права «по вопросам информационно-методического характера, а также по вопросам, связанным с организацией исполнения приказов, инструкций и других актов данного органа и вышестоящих органов управления» ${ }^{5}$.

2 Инструктивно-методические указания по служебному расследованию и ликвидации радиационных аварий (утв. Минздравом СССР 26 сентября 1980 г. № 2206-80, ВЦСПС 16 сентября 1980 г., МВД СССР 2 августа 1980 г.). - Москва, 1982.

3 Великая Отечественная / под общ. ред. В. А. Золотарева. - Москва: Терра, 1993. - С . 332.

${ }^{4}$ Государственный архив Российской Федерации (ГАРФ). - Ф. 9415. - Оп. 3с. - Д. 27. - Л. 90-95.

${ }^{5}$ Единая государственная система делопроизводства (Основные положения) (одобрено Постановлением ГКНТ СССР от 4 сентября 1973 г. № 435). - Москва: Главархив СССР, Госкомтруд СССР, Госстандарт СССР, Минприбор СССР, 1974. 
В ведомственных нормативно-правовых актах также раскрывалось, что указания содержат обязательные предписания. Так, в соответствии с п. 11 Положения о Министерстве внутренних дел СССР от 1972 года указания обязательны для исполнения министерствами внутренних дел, подразделениями, учреждениями, организациями и предприятиями ${ }^{6}$.

Исходя из анализа изученных документов, указания принимались по вопросам, требующим оперативного разрешения. Соответственно, они применялись весьма ограниченный период - до утраты необходимости в проработке поставленного вопроса. Непосредственный предмет регулирования был весьма узким - отдельная функция подразделения органа внутренних дел или даже её часть. Указаниями, к примеру, принимались и меры к наведению порядка в торговле во взаимодействии с профсоюзами (указание МВД СССР от 10 ноября 1988 года № 44 «О мерах по оказанию содействия профессиональным союзам в борьбе с негативными проявлениями в торговле и других сферах обслуживания» предлагало организовывать для специально выделенных квалифицированных сотрудников БХСС рабочие встречи с руководителями советов) [7, с. 268], и разрешались вопросы экспертизы ценности технических документальных материалов ${ }^{7}$, и рассматривались вопросы проведения пожарно-тактических учений 8 .

Указания зачастую восполняли пробелы правового регулирования. Так, указание МВД России от 14 августа 1996 г. № 1/13989

${ }^{6}$ Об утверждении Положения о Министерстве внутренних дел СССР : постановление Совмина СССР от 16 июня 1972 г. № 452 // Свод законов CCCP. - 1990. - T. 10. C. 281.

${ }^{7}$ Методические указания по экспертизе научной и практической ценности технических документальных материалов; Примерный перечень технических документальных материалов с указанием сроков и мест их хранения / Глав. архивное упр. МВД СССР. М-во просвещения РСФСР. - Москва: Учпедгиз, 1957. - 69 с.

8 Указания по проведению пожарно-тактических учений / Глав. упр. пожарной охраны МВД СССР. Оперативный отд. - Москва; Ленинград: Изд. и тип. Изд-ва М-ва коммун. хозяйства РСФСР в Перове, 1948. - 32 с. регламентировало порядок регистрации граждан СНГ, поскольку в основном ведомственном документе - Инструкции о применении Правил регистрации и снятия граждан РФ с регистрационного учета по месту пребывания и по месту жительства в пределах РФ, утвержденной приказом МВД России от 23 октября 1995 г. № 393 - порядок регистрации данной категории граждан не был предусмотрен 9 .

Представленные документы показывают, что указания как форма акта применялись в системе органов внутренних дел весьма часто и содержали зачастую правовые предписания, необходимые для функционирования органов внутренних дел.

Следующим типом распорядительных делопроизводственных документов является циркуляр - ведомственный акт, содержащий определенные предписания подчиненным органам. Он мог содержать обращение руководителя ко всем или нескольким лицам и местам, ему подчинённым. Как правило, так же, как и указание, циркуляр касался одного или нескольких вопросов ведомственного характера ${ }^{10}$, однако был более традиционной формой актов в системе органов внутренних дел, поскольку принимался на протяжении всего советского периода.

Наименование данного вида документов могло и не содержаться в тексте документа. Например, в документе от 5 июля 1923 года, использовалась формулировка «циркулярно»: «По следственной работе приходится также призадуматься, которая тоже происходит кустарным образом, и на это начальники мало обращают внимание, и в другой раз, посмотрев на материал, направляли по подсудности, который совершенно непонятный, неразборчивый или

${ }^{9}$ Воронина Т. Н. Нормативные правовые акты МВД России в механизме правового регулирования деятельности органов внутренних дел : дис. ... канд. юрид. наук: 12.00.14 / Воронина Татьяна Николаевна; Акад. упр. МВД РФ. - Москва, 2001. - С. 80.

${ }^{10}$ Цунаева Е. М. Делопроизводственная документация учреждений военного плена НКВД/МВД СССР и органов управления ими как исторический источник: 1939-1953 гг. : дис. ... канд. ист. наук: 07.00.09 / Цунаева Елена Моисеевга. - Волгоград, 2010. - C. 170. 
перепутанный, эти явления можно заключать тем, что пишущий заключение и утверждал, он фактически указывает статью неправильно, за что нам говорят поступающие с мест материалы, а нам нужно более обращать внимание на Уголовно-процессуальный кодекс, мы не должны нарушать тех определённых рамок» ${ }^{11}$. Данный акт содержит предписание об имеющих место недостатках в работе органов следствия, а также носит рекомендательный характер о том, что следует исполнять нормы действующего законодательства.

В циркулярах конца 80-х годов XIX века также отражена рекомендательная составляющая данного типа документов: «Циркуляры МВД губернаторам от 28 июля 1887 года № 3153 и от 7 января 1889 года № 69, в которых было рекомендовано организовать в губернских городах подготовительные школы для полицейских урядников» [4, с. 71].

В литературе отмечена особенность данного типа документа: многостраничная мотивирующая часть документа вместо лаконичных формулировок [6, с. 239].

Вопросы, разрешаемые в рамках циркуляров, касались усовершенствования структуры и работы органов внутренних дел, а также отдельных подразделений: материально-технического, кадрового, следственного и т.п. Циркуляры носили недолговременный характер, поскольку, регулировали узконаправленный предмет рассмотрения.

Директива - это общее руководящее указание, издаваемое органом управления, в том числе и органами внутренних дел НКВД-МВД.

Директивы принимались по всем направлениям деятельности, однако предметом регулирования являлась выработка основных руководящих положений, входящих в компетенцию органа государственной власти.

Анализ источников позволяет сделать вывод, что директивы как тип документов

${ }^{11}$ Государственный архив административных органов Свердловской области (ГААСО). - Ф. Р-128. - Оп. 1. - Д. № 52 . - Л. 61.

12 Директива о боевой подготовке частей ВПО и ГПО НКВД СССР / Глав. упр. пожарной охра- начали разрабатываться только в конце 1930-х годов ${ }^{12}$ и применялись до конца советского периода.

В 1997 году нормативно было закреплено, что директива содержит нормативные предписания ориентирующего характера, определяющие перспективы развития системы Министерства, а также основные направления ее деятельности ${ }^{13}$.

Содержание директивы имело нормативные предписания, например, о запрете определённых действий (о запрете использования заключённых в качестве бесплатной рабочей силы и активизации работы по выявлению нарушений со стороны личного состава и наказанию виновных) ${ }^{14}$; об установлении нового порядка действий (Директива МВД СССР от 20 апреля 1946 г. № 97 «О порядке оформления материалов и направлении на спецпоселение лиц, служивших в немецкой армии, “власовцев”, легионеров и полицейских» ${ }^{15}$ ); об определении нового круга задач ведомств (в Директиве НКВД СССР от 18 июля 1941 г. № 169 перед особыми отделами ставилась задача решительной борьбы с дезертирством, шпионажем и предательством в частях Красной Армии, особенно в прифронтовой полосе $\left.{ }^{16}\right)$. Также всегда директива содержала такую формулировку, как «предлагаю», что отражает рекомендательную характеристику данного типа документа.

Таким образом, директива как форма акта является устоявшимся типом ведом-

ны НКВД СССР. - Москва: Отд. подготовки ГУПО НКВД СССР, 1937. - 18 с.; Директива о задачах физкультурной спортивной работы в частях военизированной и городской пожарной охраны НКВД СССР / Глав. упр. пожарной охраны НКВД СССР. - Москва; Ленинград: Гостранстехиздат, 1937. - 39 с.

${ }^{13} \mathrm{O}$ мерах по реализации Постановления Правительства Российской Федерации от 13 августа 1997 г. № 1009 : приказ МВД РФ от 3 октября 1997 г. № 642 // Москва: МВД РФ, 1997.

${ }^{14}$ ГАРФ. - Ф. 9401. - Оп. 1а. - Д. 443. - Л. 190.

${ }^{15}$ ГАРФ. - Ф. Р-9401. - Оп. 12. - Д. 207. - Т. 2. 1946 г. - Л. 1-1 об.

${ }^{16}$ Министерство внутренних дел. 1902-2002. Исторический очерк / под общ. ред. Р. Г. Нургалиева. - Москва: Объединенная редакция МВД России, 2008. - C. 342. 
ственного документа и регулирует вопросы ориентирующего характера.

Близкими по предмету регулирования к вышеназванным являются и письменные приказания, которые не являются распространенной формой документов. Они касаются отдельных частных вопросов и обращены к конкретным должностным лицам.

Так же как и указания и директивы, письменные приказания использовались как форма актов с конца 1930-х годов ${ }^{17}$. Основное отличие - то, что данная форма акта применялась в системе органов внутренних дел и в XIX веке, о чем свидетельствует Положение о полицейских урядниках от 9 июня 1878 г., в котором предусматривалось, что урядники должны исполнять полицейские обязанности, надзирать за действиями сотских и десятских, равно как руководить ими, причем они имеют право давать приказания также волостным старшинам [10, c.39]. Указанная форма актов отражает преемственность в работе органов внутренних дел не только при фактическом исполнении обязанностей, но и при составлении документов.

Порядок издания приказаний был регламентирован лишь в 1979 году приказом МВД СССР от 6 марта 1979 г. № 80 «Об ут верждении Устава внутренней службы органов внутренних дел» ${ }^{18}$. Основными критериями приказаний назывались их точность, чёткость и понятность. При этом указывалось, что «приказания отдаются, как правило, в порядке подчинённости» ${ }^{19}$.

Содержательно приказания вносили изменения в существующий порядок деятельности органов внутренних дел. Например, Приказание ГУМ НКВД СССР от 8 марта 1943 года № 15 предусматривало переход на

${ }^{17}$ Сметный справочник по дорожному строительств : Утв. приказанием по Глав. упр. шоссейных дорог НКВД СССР от 11 июля 1936 г. за № 107 как обязательный при сост. смет к техн. проектам по дор. строительству / СССР. Нар. ком. внутр. дел. Глав. упр. шоссейных дорог Гушоссдор. - Москва: Гушоссдор, 1936. $-631 \mathrm{c}$.

${ }^{18}$ Об утверждении Устава внутренней службы органов внутренних дел : приказ МВД СССР от 6 марта 1979 г. № 80 [Электронный ресурс] // СПС «Консультант Плюс»

${ }^{19}$ См.: п. 8 приказа МВД СССР от 6 марта 1979 г. новое форменное обмундирование ${ }^{20}$; Приказание МВД СССР № 74 касалось невыполнения директивы МВД СССР по снижению заболеваемости и смертности среди военнопленных от 11 апреля 1946 г.

Предусматривалось создание комиссии по проверке работы всех звеньев лагеря по выполнению директив МВД СССР по содержанию, питанию, трудовому использованию и медико-санитарному обслуживанию военнопленных ${ }^{21}$.

Таким образом, в системе органов внутренних дел сложился внушительный перечень распорядительных делопроизводственных документов, содержащих правовые предписания, но не обладающих признаком нормативности. Более того, исторический анализ представленных типов документов показывает, что в системе органов внутренних дел отдельные группы документов оставались неизменными, другие являлись новой формой принятия правовых решений. Это свидетельствует о том, что в настоящее время, учитывая традиции системы органов внутренних дел, для единообразного применения необходимо сформировать комплекс нормативно-правовых актов общеобязательного характера, а также комплекс правовых актов, обязательных для исполнения только должностными лицами, подразделениями органов внутренних дел, определить специфику каждого типа документов и, при необходимости, разработать их унифицированные формы и обозначить предмет или характер регулирования. В правотворческой практике Министерство лишь использует отдельные виды актов, которые наилучшим образом соответствуют его компетенции [3, с. 54].

Проведённый ретроспективный анализ некоторых видов документов органов внутренних дел может быть использован для совершенствования действующего законодательства при условии сохранения сформировавшихся традиционных форм актов ведомственного уровня.

${ }^{20}$ Яковлев А.Н., Кокурин А.И., Петров Н.В. Лубянка. Органы ВЧК-ОГПУ-НКВД-НКГБ-МГБ-МВДКГБ : справочник. 1917-1991. - Москва: МФД, 2003. - C. 79.

${ }^{21}$ ГА РФ. - Ф. 9401. - Оп. 1. - Д. 780. - Л. 266-267. № 80 . 


\section{Список литературь}

1. Домченко А. С. Виды нормативных и иных неиндивидуализированных правовых актов публичного управления федерального уровня // Российское право: образование, практика, наука. - 2017. - № 6. - С. 52-59.

2. Канунникова Н. Г. К вопросу об управлении деятельностью органов внутренних дел и правовом воспитании их сотрудников // Административное право и процесс. - 2015. - № 10. - С. 30-33.

3. Максимов А. А. Значение и роль правотворчества и правоприменения в системе органов внутренних дел // Российская юстиция. - 2018. - № 5. - С. 51-54.

4. Нахимов А. П., Кирнос А. В., Колесников В. А. Образовательные организации системы МВД / НКВД в Воронежском регионе (1888-1942 гг.) : монография. - Воронеж: Воронежский институт МВД России, 2017. - 382 с.

5. Ноздрачёв А. Ф. Административные акты: понятие, признаки, динамика // Административные процедуры и контроль в свете европейского опыта / под ред. Т.Я. Хабриевой и Ж. Марку. - Москва: Статут, 2011. - 320 с.

6. Осипов М. В. Циркуляры главного тюремного управления МВД как источник по истории пенитенциарной системы России в период пореформенной модернизации (1979-1985) // Известия Самарского научного центра Российской академии наук. - 2009. - Т. 11. - № 2. - С. 239-242.

7. Постников С. В. Историко-правовой анализ организации органами милиции профилактических мероприятий в экономической сфере в 60-70-е годы XX века // Вестник Нижегородской академии МВД России. - 2014. - № 3 (27). - С. 264-269.

8. Студеникина M. С. Нормативные правовые акты управления как форма реализации исполнительной власти // Административное право и процесс. - 2014. - № 2. - С. 6-11.

9. Тарасенко О. В., Данилов И. А. Вопросы управления федеральной собственностью // Юрист. - 2017. - № 19. - С. 14-15.

10. Тарасов И. Т. Полиция России. История, законы, реформы, перспективы. - Москва: Книжный мир, 2011. - 256 с.

\section{References}

1. Domchenko A. S. Vidy normativnykh i inykh neindividualizirovannykh pravovykh aktov publichnogo upravleniya federal'nogo urovnya // Rossiyskoye pravo: obrazovaniye, praktika, nauka. - 2017. - № 6. - S. 52-59.

2. Kanunnikova N. G. K voprosu ob upravlenii deyatel'nost'yu organov vnutrennikh del i pravovom vospitanii ikh sotrudnikov // Administrativnoye pravo i protsess. - 2015. - № 10. - S. 30-33.

3. Maksimov A. A. Znacheniye i rol' pravotvorchestva i pravoprimeneniya v sisteme organov vnutrennikh del // Rossiyskaya yustitsiya. - 2018. - № 5. - S. 51-54.

4. Nakhimov A. P., Kirnos A. V., Kolesnikov V. A. Obrazovatel'nyye organizatsii sistemy MVD / NKVD v Voronezhskom regione (1888-1942 gg.) : monografiya. - Voronezh: Voronezhskiy institut MVD Rossii, 2017. - 382 s.

5. Nozdrachov A. F. Administrativnyye akty: ponyatiye, priznaki, dinamika// Administrativnyye protsedury i kontrol' v svete yevropeyskogo opyta / pod red. T.Ya. Khabriyevoy i Zh. Marku. Moskva: Statut, 2011. - 320 s.

6. Osipov M. V. Tsirkulyary glavnogo tyuremnogo upravleniya MVD kak istochnik po istorii penitentsiarnoy sistemy Rossii v period poreformennoy modernizatsii (1979-1985) // Izvestiya Samarskogo nauchnogo tsentra Rossiyskoy akademii nauk. - 2009. - T. 11. - № 2. - S. 239-242.

7. Postnikov S. V. Istoriko-pravovoy analiz organizatsii organami militsii profilakticheskikh meropriyatiy v ekonomicheskoy sfere v 60-70-ye gody XX veka // Vestnik Nizhegorodskoy akademii MVD Rossii. - 2014. - № 3 (27). - S. 264-269.

8. Studenikina M. S. Normativnyye pravovyye akty upravleniya kak forma realizatsii ispolnitel'noy vlasti // Administrativnoye pravo i protsess. - 2014. - № 2. - S. 6-11.

9. Tarasenko O. V., Danilov I. A. Voprosy upravleniya federal'noy sobstvennost'yu // Yurist. 2017. - № 19. - S. 14-15.

10. Tarasov I. T. Politsiya Rossii. Istoriya, zakony, reformy, perspektivy. - Moskva: Knizhnyy mir, 2011. $-256 \mathrm{~s}$.

(C) Пестова О.А., 2019

Статья поступила в редакцию 15.03.2019. 